\title{
Pengendalian Stok Spareparts Mobil Dengan Metode EOQ dan Min-Max Inventory
}

\author{
Mia Juliana Siregar \\ Jurusan Teknik Industri, Universitas Universal, Sungai Panas, Batam, Kepulauan Riau \\ Koresponden email: mia_juliana.1988@yahoo.com
}

Diterima: 7 Juli 2021

Disetujui: 16 Juli 2021

\begin{abstract}
This research was conducted in the distributor of car spare parts and the object studied was car glass glue. This item is a product that experiences a stacking stock in the warehouse, so it needs inventory control to reduce the stacking stock. The character of the product which does not have expired date as long as it is not used and small size, the company never make an optimal estimate of the order, so the activity of ordering goods is only based on its own estimates. The method used in this research is EOQ to obtain the economical amount of the product to be ordered. The calculation process using EOQ method is done against 2019 sales data predicted to 2021 using Trend Linear forecasting method, with function form is $Y=1,8776 x+256,21$. Furthermore, the minimum and maximum stock quantity is determined using the Min-Max Inventory method. From the result of the study found that the economic Q per ordered is 386 pcs with the frequency of bookings 8 times a year. The minimum inventory is 108 pcs and the maximum is 144 pcs with the amount of safety stock is 72 pcs and ROP is 108 pcs. By using EOQ method, the company can make savings of Rp3,939,330 per year and reduce storage cost by Rp10,119,635 per year.
\end{abstract}

Keywords: inventory, safety stock, EOQ, ROP, Min-max method

\begin{abstract}
Abstrak
Penelitian ini dilakukan di distributor spare part mobil dengan objek yang diteliti adalah lem kaca mobil. Item ini merupakan produk yang mengalami penumpukan stok di gudang penyimpanan, sehingga dibutuhkan pengendalian persediaan untuk mengurangi penumpukan stok. Karakter produk yang tidak memiliki kadaluwarsa selama tidak dipakai, ukurannya yang kecil membuat perusahaan tidak pernah melakukan estimasi pemesanan yang optimal, sehingga kegiatan pemesanan barang hanya berdasarkan perkiraan sendiri. Penelitian ini dilakukan dengan menggunakan metode EOQ untuk mendapatkan jumlah ekonomis dari produk yang harus dipesan. Proses perhitungan dengan menggunakan metode EOQ dilakukan terhadap data penjualan 2019 yang diramalkan ke tahun 2021 dengan menggunakan metode peramalan kuantitatif trend linear dengan persamaan $\mathrm{Y}=1,8776 \mathrm{x}+256,21$. Selanjutnya ditentukan kuantitas stok minimum dan maksimum menggunakan metode Min-Max Inventory. Dari hasil penelitian ditemukan bahwa Q yang yang ekonomi sekali pesan adalah sebesar 386 pcs dengan frekuensi pemesanan 8 kali dalam setahun. Inventory minimum adalah sebaiknya 108 pcs dan maksimum adalah 144 pcs dengan jumlah safety stock adalah sebesar 72 pcs dengan ROP 108 pcs. Dengan menggunakan metode EOQ, perusahaan dapat melakukan penghematan sebesar Rp3.939.330 dalam setahun dan mengurangi baya penyimpanan sebesar Rp10.119.635 per tahun.
\end{abstract}

Kata kunci: inventory, safetystock, EOQ, ROP, Min-max method

\section{Pendahuluan}

Dalam menjalankan sebuah badan usaha, perusahaan memerlukan produk yang harus selalu tersedia ketika konsumen membutuhkannya. Ketersediaan produk tentu akan berkaitan dengan bagaimana perusahaan mengendalikan dan mengatur stok barang di gudang penyimpanan. Pengaturan atau controlling yang baik akan menghasilkan loyalitas konsumen yang merupakan keuntungan bagi perusahaan. Selain itu perencanaan persediaan juga akan mempengaruhi aktivitas sehari - hari perusahaan tersebut.

Persediaan perlu dikendalikan agar memberikan stok yang selalu tersedia kapanpun dibutuhkan. Jika persediaan tidak dapat dikendalikan maka akan menghasilkan kondisi dimana perusahaan akan kekurangan stok sehingga tidak dapat memenuhi kebutuhan konsumen atau kelebihan stok yang mengakibatkan 
penumpukan digudang penyimpanan. Penumpukan barang baik produk jadi atau bahan baku akan mengurangi ketersediaan ruang yang dapat dimanfaatkan oleh perusahaan. Penumpukan produk atau barang juga akan membuat perusahaan harus menumpuk modal bisnis yang seharusnya dapat dipergunakan.

Distributor mobil yang dibahas dalam penelitian ini memiliki masalah dalam mengendalikan stok barang, salah satu diantaranya adalah lem kaca mobil. Satu jenis produk ini memiliki stok yang selalu berlebihan, sehingga menumpuk digudang. Akan tetapi, perusahaan juga masih tetap melakukan pemesanan kembali (reorder) barang jenis ini tanpa mengetahui sebaiknya berapa banyak kuantitas lem yang harus dipesan dalam satu kali pemesanan.

Penelitian ini dilakukan untuk menemukan berapa jumlah atau kuantitas lem yang harus dipesan dalam satu kali pemesanan dan berapa banyak stok minimum dan maksimum lem kaca mobil yang sebaiknya di simpan di gudang penyimpanan. Persediaan merupakan tempat menyimpan material baik bahan mentah, barang sedang diproses (work in process), dan barang jadi yang menunjang kelancaran aktivitas perusahaan [1]. Bagi perusahaan persediaan merupakan bagian yang sangat penting karena menjadi kunci keberhasilan, sehingga perlu melakukan pengawasan dalam pengendalian persediaan agar tidak terjadi kelalaian stok [2] dan mempengaruhi kelancaran kegiatan produksi [3].

Pengendalian persediaan merupakan metode dalam menganalisis persediaan yang mencakup aktivitas pelaksanaan, pengawasan, perencanaan kebutuhan bahan baku yang harus dipenuhi ketika dibutuhkan [4]. Aktivitas pengendalian persediaan bukanlah hal yang mudah, karena mempengaruhi cost yang harus ditanggung akibat adanya inventory [5]. Apabila persediaan terlalu besar akan menimbulkan penumpukan dana yang menganggur (meningkatkan biaya penyimpanan), namun bila kekurangan persediaan akan menyebabkan terhentinya proses produksi, tertundanya penjualan dan dampak terburuk adalah kehilangan pelanggan [6].

Metode pengendalian persediaan terdiri dari beberapa, diantaranya Economic Order Quantity (EOQ) yang merupakan teknik pengadaan bahan baku dengan menentukan berapa jumlah pesanan ekonomis setiap kali pemesanan dengan frekuensi yang sudah ditentukan serta kapan dilakukan pemesanan kembali [7]. Model ini menggunakan asumsi sederhana, yaitu (1) tingkat permintaan konstan, (2) tidak ada perubahan biaya ketika melakukan pemesanan, (3) kapasitas produksi dan persediaan tidak terbatas, (4) tidak terjadi kekurangan stok [8]. Metode ini berusaha memperkecil biaya-biaya pemesanan (ordering cost) dan biaya-biaya penyimpanan (carrying cost) [5].

Selain model EOQ dikenal juga metode lain, yaitu metode Min-Max. Metode ini didasarkan atas asumsi bahwa persediaan bahan baku berada ditingkat maksimum dan minimum [9]. Jika tingkat maksimum dan minimum persediaan sudah ditetapkan, maka pemesanan dapat dilakukan dengan terkontrol. Hal ini menghindari persediaan yang terlalu besar atau terlalu kecil di gudang agar tidak terjadi pemborosan biaya persediaan [10]. Beberapa tahapan dalam model metode ini adalah (1) menentukan safety stock, (2) menentukan persediaan minimum (minimum inventory), (3) menentukan persediaan maksimum (maximum inventory) yang diperbolehkan untuk disimpan [9].

Inventory perusahaan akan mempengaruhi dan atau dipengaruhi oleh jumlah output yang akan dihasilkan oleh perusahaan. Oleh sebab itu, dalam menentukan berapa banyak pcs atau unit produk yang harus disimpan, perusahaan perlu mengetahui permintaan output selama beberapa periode. Aktivitas peramalan juga diperlukan dalam menentukan jumlah output. Peramalan berarti memperkirakan jumlah permintaan satu atau lebih produk dalam beberapa periode [11]. Metode peramalan terdiri dari kualitatif yang didasarkan ada data kualitatif masa lalu dan kuantitatif yang menggunakan perumusan matematis atau statistika [12]. Peramalan kuantitatif sendiri dibedakan menjadi beberapa kelompok diantaranya pola hubungan variabel dengan deret waktu atau time series, yang terdiri dari rata-rata bergerak (single moving average) dan rata-rata bergerak tertimbang (weighted moving average) [12] dan peramalan berdasarkan hubungan antara variabel yang diperkirakan dengan variabel lain yang mempengaruhinya (metode korelasi), diantaranya pola siklis, pola musiman, pola horizontal, dan pola trend [13].

\section{Metode Penelitian}

Penelitian ini menggunakan tool forecasting untuk memprediksi kebutuhan lem kaca mobil ke depannya. Model forecasting yang digunakan adalah metode korelasi trend linear. Setelah dilakukan forecasting, selanjutnya hasil forecasting akan divalidasi dengan metode tracking signal. Tracking signal yang positif menunjukkan nilai aktual lebih besar dibanding hasil proyeksi, dan tracking signal negatif menunjukkan hasil peramalan lebih besar dibanding aktual. 


$$
\begin{gathered}
\text { RSFE }=\Sigma(\text { Act. Demand }- \text { Forcst Demand }) \\
T S=\frac{R S F E}{M A D}
\end{gathered}
$$

Penelitian ini juga akan menghitung besar penyimpangan yang terjadi pada saat pemesanan lem kaca menggunakan Standar Deviasi (STD) [14].

$$
\sigma_{L=} \sigma_{d} \sqrt{L}
$$

Dimana:

$\sigma_{L=}$ standar deviasi $\mathrm{L}=$ leadtime

$\sigma_{d=}$ standar deviasi per hari

Setelah itu akan menghitung jumlah pesanan ekonomis dengan menggunakan model EOQ [14].

$$
E O Q=\sqrt{\frac{2 D S}{H}}
$$

Dimana:

$\mathrm{D}=$ Permintaan tahunan $\mathrm{S}=$ Biaya pemesanan

$\mathrm{H}=$ Biaya penyimpanan

Selanjutnya akan ditentukan Reorder Point untuk mengetahui kapan harus melakukan pemesanan kembali. [14]

$$
\begin{gathered}
S S=\sigma_{L} \times \text { Service factor } \\
R O P=S S+\left(\begin{array}{l}
L \\
x Q
\end{array}\right)
\end{gathered}
$$

Selanjutnya dilakukan perhitungan min-max inventory, untuk mengetahui berapa minimum stok sehingga dilakukan pemesanan kembali dan maksimum stok yang dapat disimpan di gudang [9].

Dimana:

$$
\text { Minimum Inventory }=\frac{(T x L)}{30}+S S
$$

$\mathrm{T}=$ Pemakaian barang rata-rata per periode

$\mathrm{C}=$ Leadtime

$$
\text { Maximum Inventory }=\frac{2(T x L)}{30}+S S
$$

Data yang digunakan adalah data pemesanan dan penjualan tahun 2019 karena data pada tahun ini lebih lengkap (Tabel 1). Persediaan awal lem kaca ini adalah 2.500 pcs. Aktivitas pemesanan lem kaca biasanya dilakukan tiga kali dalam setahun, yaitu di bulan Januari 2019 $=859$ pcs, Mei 2019=1.019 pcs, dan Oktober $=$ 1.111 pcs. Lem kaca mobil ini memiliki kondisi aktual yang menumpuk di gudang. Leadtime atau masa tenggang untuk lem kaca yaitu 4 hari.

Tabel 1. Data penjualan tahun 2019

\begin{tabular}{cc|cc}
\hline Bulan & Penjualan & Bulan & Penjualan \\
\hline Jan & 301 & Jul & 260 \\
Feb & 372 & Aug & 299 \\
Mar & 232 & Sep & 269 \\
Apr & 173 & Okt & 280 \\
Mei & 160 & Nov & 275 \\
Jun & 281 & Des & 319 \\
\hline
\end{tabular}

Sumber: [15] 


\section{Hasil dan Pembahasan}

Sebelum melakukan perhitungan peramalan dan pengendalian persediaan, penelitian ini mencari akar masalah mengapa stok lem kaca mobil ini bisa menumpuk. Proses analisa akar masalah dilakukan dengan menggunakan fishbone diagram (Gambar 1).

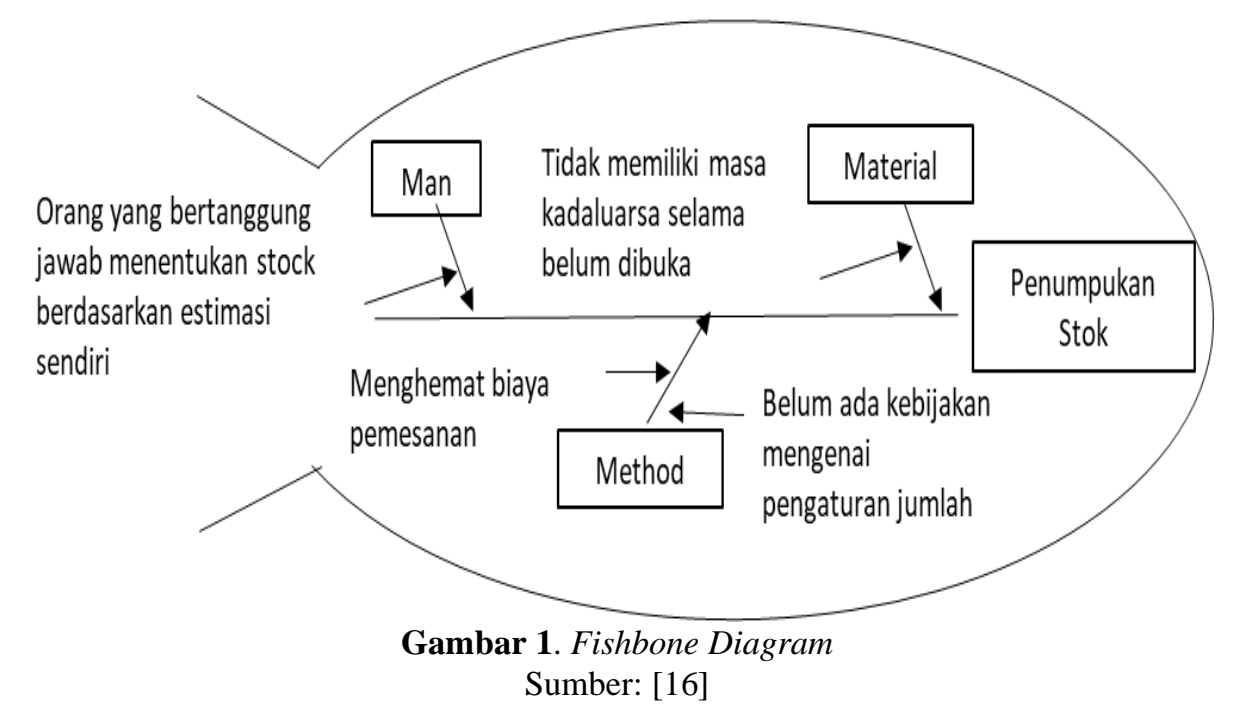

Dari diagram tulang ikan dapat diketahui bahwa perusahaan tidak mempunya kebijakan dalam menentukan jumlah pesanan, sehingga kuantitas pemesanan dilakukan hanya berdasarkan tebak estimasi oleh pihak yang bertanggung jawab terhadap pemesanan barang. Jenis sparepart yang tidak memiliki masa kadaluwarsa ini juga membuat perusahaan tidak mempermasalahkan kuantitas pesanan yang diakibatkan oleh anggapan bahwa lem tidak akan kadaluwarsa jika tidak dibuka. Hal inilah yang membuat perusahaan beranggapan untuk memesan dalam jumlah besar untuk menghemat biaya.

Tabel 2. Forecasting penjualan Tahun 2021

\begin{tabular}{cccccc}
\hline Bulan & $\begin{array}{c}\text { Actual } \\
\text { Demand }\end{array}$ & $\begin{array}{c}\text { Forcasting } \\
\text { Demand }\end{array}$ & MAD & RESFE & TS \\
\hline Jan & 301 & 258 & 3,576 & 43 & 12 \\
Feb & 372 & 260 & 9,336 & 112 & 12 \\
Mar & 232 & 262 & 2,487 & -30 & -12 \\
Apr & 173 & 264 & 7,560 & -91 & -12 \\
Mei & 160 & 266 & 8,800 & -106 & -12 \\
Jun & 281 & 267 & 1,127 & 14 & 12 \\
Jul & 260 & 269 & 0,779 & -9 & -12 \\
Aug & 299 & 271 & 2,314 & 28 & 12 \\
Sep & 269 & 273 & 0,342 & -4 & -12 \\
Okt & 280 & 275 & 0,418 & 5 & 12 \\
Nov & 275 & 277 & 0,155 & -2 & -12 \\
Des & 319 & 279 & 3,355 & 40 & 12 \\
\hline
\end{tabular}

Dari fishbone diagram, selanjutnya akan dilakukan prediksi atau forecasting penjualan lem kaca, yaitu tahun 2021 dengan metode Trend Linear dihasilkan bentuk fungsi $Y=1,8776 x+256,21$. Hasil forecasting yang diperoleh terlihat pada Tabel 2. Nilai Tracking Signal (TS) adalah 12 dan -12 memiliki jumlah yang seimbang (12 sebanyak 6 bulan dan -12 sebanyak 6 bulan). Dari nilai TS ini dinyatakan bahwa ada 6 bulan nilai aktual permintaan lebih besar daripada ramalan dan ada sebanyak 6 bulan nilai aktual permintaan lebih kecil dari peramalan. 
Besarnya nilai penyimpangan (Standar Deviasi) permintaan yang terjadi ketika pemesanan lem kaca mobil ada sebesar 56 pcs. Sehingga dari sini dapat ditentukan nilai Safety Stock dengan service level diestimasi di level $90 \%$, service factor $=1,2816$ sebaiknya sebesar $=72$ pcs. Pemesanan bahan baku yang ekonomis dihitung dengan menggunakan metode EOQ. Rata-rata permintaan per bulan adalah sebesar 268 pcs lem kaca dan biaya pemesanan yang dikeluarkan setiap kali memesan adalah sebesar Rp 300.000. Biaya simpan diasumsikan 20\% dari harga unit lem kaca Rp 65.000. Sehingga jumlah quantity ekonomis = 386 pcs lem kaca mobil.

Dengan jumlah pesanan ekonomis sebanyak 386 pcs, total biaya persediaan perusahaan menjadi sebesar Rp 3.341.576 per tahun. Dari nilai EOQ dapat ditentukan sebaiknya frekuensi pemesanan dilakukan sebanyak 8 kali (D/EOQ) dalam 1 tahun. Pemesanan produk lem kaca dapat dilakukan oleh perusahaan pada titik kuantitas tertentu. Berdasarkan perhitungan yang dilakukan diperoleh ROP perusahaan adalah sebesar 108 pcs. Dengan menggunakan metode min-max inventory akan ditemukan berapa persediaan minimal dan persediaan maksimal perusahaan.

Persediaan minimum $=108$ pcs dan persediaan maksimum $=144 \mathrm{pcs}$

Dari hasil perhitungan dapat dibandingkan antara biaya tanpa menggunakan metode EOQ dan menggunakan EOQ seperti pada (Tabel 3).

Tabel 3. Perbandingan biaya

\begin{tabular}{lll}
\hline Penjelasan & Sebelum EOQ & Sesudah EOQ \\
\hline Frekuensi & 3 kali & 8 kali \\
Quantity & 1.164 pcs & 386 pcs \\
SS & - & $72 \mathrm{pcs}$ \\
ROP & - & 108 pcs \\
B.persediaan & Rp 7.280.907 & Rp 3.341.576 \\
B.simpan & Rp15.132.000 & Rp5.012.365 \\
Inv. min & - & 108 pcs \\
Inv. maks & - & 144 pcs \\
\hline \multicolumn{3}{c}{}
\end{tabular}

\section{Kesimpulan}

Kebijakan yang dijalankan selama ini di perusahaan menunjukkan pengeluaran yang sangat besar dalam manajemen inventory. Dari hasil analisis fishbone diagram ditunjukkan penumpukan jenis item lem kaca dapat diketahui faktor-faktor yang mempengaruhi penumpukan barang, yaitu: man: estimasi dilakukan atas persepsi sendiri; method: belum ada kebijakan yang mengatur jumlah pemesanan dalam sekali pesan, dan material: sifat dari sparepart yang tidak kadaluwarsa. Dengan penerapan metode EOQ melalui proses peramalan permintaan dalam setahun ke depan, maka perusahaan mampu menghemat Rp3.939.330 dalam pengadaan produk per tahun dan mampu mengurangi biaya penyimpanan barang sebesar Rp10.119.635 per tahun.

\section{Referensi}

[1] A. Wijaya, M. Arifin and T. Soebijono, "Sistem Informasi Perencanaan Persediaan Barang," Sistem Informasi, vol. 2, pp. 14-20, 2013.

[2] R. Noviani, Y. N. Nasution and A. Rizki, "Klasifikasi Persediaan Barang Menggunakan Analisis Always Better Control (ABC) dan Prediksi Permintaan Dengan Metode Monte Carlo (Studi Kasus : Persediaan Obat Pada Apotek Mega Rizki Tahun 2016)," J. Eksponensial, vol. 8, no. 2, pp. 103-110, 2017.

[3] S. Suryani and D. Can, "Analisis Pengendalian Persediaan Sistem Manajemen Persediaan Bahan Baku Kemasan," Intech Teknik Industri, vol. 4, no. 2, p. 65, 2018.

[4] H. Al-Khazraji, C. Cole and W. Guo, "Dynamics Analysis of a Production Inventory Control System With Two Pipelines Feedback," Emerald Insight, vol. 46, pp. 1632-1653, 2017.

[5] D. Niarto, A. L. and Heriyanto, "Manajemen Persediaan Suku Cadang Alat Berat PT United Tractors, Tbk. Cabang Samarinda," J. Eonomia, vol. 5, no. 3, pp. 10-17, 2016. 
[6] E. Herjanto, Manajemen Operasi. Edisi Ketiga, Jakarta: Grasindo, 2015.

[7] N. Apriyani and A. Muhsin, "Analisis Pengendalian Persediaan Bahan Baku dengan Metode Economic Order Quantity dan Kanban Pada PT Adyawinsa Stamping Industries," J. Opsi, vol. 10, no. 2, p. 128, 2017.

[8] A. Eunike, Perencanaan Produksi dan Pengendalian Persediaan, Malang: Universitas Brawijaya Press, 2018.

[9] A. P. Kinanthi, D. Herlina and F. A. Mahardika, "Analisis Pengendalian Persediaan Bahan Baku Menggunakan Metode Min-Max (Studi Kasus PT Djitoe Indonesia Tobacco)," Performa, vol. 15, no. 2, pp. 87-92, 2016.

[10] F. Prima and A. Sindikia, "Pengendalian Persediaan Pozzolan di PT Semen Padang," J. Optimasi Sistem Industri, vol. 13, no. 2, 2014.

[11] A. Nurlifa and S. Kusumadewi, "Sistem Peramalan Jumlah Penjualan Menggunakan Metode Moving Average Pada Rumah Jilbab Zaky," JURNAL INOVTEK POLBENG - SERI INFORMATIKA, Vols. VOL. 2, NO. 1 , no. Juni 2017, pp. 18-26, 2017.

[12] D. Pianda, Optimasi Perencanaan Produksi pada Kombinasi Produk dengan Metode Linear Programming, CV Jejak, 2018.

[13] A. Ishak, Manajemen Operasi (Edisi Kedua), Medan: USU Press, 2015.

[14] J. Puspika and D. Anita, "Inventory Control Dan Perencanaan Persediaan Bahan Baku Produksi Roti Pada Pabrik Roti Bobo Pekanbaru," Jurnal Ekonomi, Vols. Volume 21, Nomor 3 , no. September 2013, pp. 1-15, 2013.

[15] Hendy, Pengendalian Persediaan Pada Sukucadang Sikatitan Dengan Metode Economic Order Quantity (EOQ) (Studi Kasus PT.Asuki Batam), Batam, Kepulauan Riau: Universitas Universal, 2019.

[16] M. Juliana, Pengendalian Stok Sparepart dengan Metode EOQ dan Min Max Inventory, Batam, 2021.

[17] Haizer, Jay and R. Bary, Operation Management: Manajemen Operasi, Jakarta: Salemba Empat, 2005. 